POTENSI PIGMEN CASSIAVERA PADA MINUMAN JAHE INSTAN SEBAGAI MINUMAN FUNGSIONAL

\title{
Potency of Cassiavera pigment in Ginger drink instant as a functional drink
}

Firdausni*, Failisnur dan Yulia Helmi Diza ${ }^{1}$ )

1. Balai Riset dan Standardisasi Industri Padang

JI. Raya LIK Ulu Gadut No. 23 Telp. (0751) 72201 Fax.(0751) 71320 Padang 25164

* e-mail: firda bio@yahoo.com

Diterima: 14 September 2011, Revisi akhir: 7 November 2011

\section{ABSTRAK}

Cassiavera (Cinnamomum burmannii) mengandung pigmen berwarna coklat kemerahan sampai coklat tua yang digunakan sebagai bahan tambahan pada minuman jahe instan. Pengambilan pigmen dengan maserasi air pada suhu awal $25-27^{\circ} \mathrm{C}$ dan $85-100^{\circ} \mathrm{C}$ dengan lama maserasi 24, 48 dan 72 jam. Filtrat cassiavera dengan intensitas warna optimal yang didapatkan selanjutnya ditambahkan pada jahe bubuk dengan perbandingan antara jahe bubuk dan filtrat cassiavera b/v (10:1), (10:2) dan (10:3). Potensi pigmen cassiavera pada jahe instan dilihat dari intensitas warna dengan menggunakan spektrofotometer, uji total fenol dan tingkat kesukaan fanelis terhadap aroma, warna, dan rasa yang dihasilkan. Hasil penelitian menunjukkan bahwa perlakuan lamanya maserasi berpengaruh nyata terhadap intensitas warna produk. Pada pengambilan pigmen cassiavera didapatkan perlakuan terbaik pada maserasi dengan air pada suhu $85-100^{\circ} \mathrm{C}$ selama 48 jam dan perbandingan jahe bubuk dengan filtrat cassiavera dalam pembuatan jahe cassiavera instan adalah 10:3 (b/v) dengan intensitas warna tertinggi 0,3813, memiliki total fenol 26,51 ppm, aroma, warna, dan rasa yang disukai oleh panelis dengan nilai rata rata 3,$40 ; 3,47$, dan 3,20 . Pengujian intensitas warna menggunakan spektrofotometer yang diukur pada panjang gelombang $556 \mathrm{~nm}$ menunjukkan intensitas warna antara 0.03450.3813, dan total fenol antara 20,47-26,51 ppm.

Kata Kunci: Pigmen cassiavera, maserasi, jahe cassiavera instan, minuman fungsional

\section{ABSTRACT}

Cassiavera (Cinnamomum burmannii) contains reddish brown to dark brown pigment that can be used as additives in instant ginger drink. The pigment was generated by maceration method in water at initial temperature $25-27^{\circ} \mathrm{C}$ and $85-100^{\circ} \mathrm{C}$ with maceration time of 24, 48 and 72 hours. Cassiavera filtrate with optimal color intensity was then added to the ginger powder in the ratio $w / v(10: 1),(10: 2)$ and (10:3). The potency of cassiavera pigment in the instant ginger was seen from the color intensity by using a spectrophotometer, test of total phenols and panelist preference level of aroma, color, and flavor generated. Results of the research showed that the treatment time of maceration significantly affected the color intensity of the product. The best treatment of cassiavera pigment generating was found on maceration with water at temperature $85-100^{\circ} \mathrm{C}$ for 48 hours and comparison of ginger powder and cassiavera filtrate 10:3 (w/v) with the highest color intensity 0, 3813 and the color preferred by the panelists. Total phenol was $26.51 \mathrm{ppm}$, with average values of organoleptic test of taste, color, and aroma were 3.20, 3.40, and 3.40 respectively. The Color intensity was measured by using a spectrophotometer at a wavelength of $556 \mathrm{~nm}$ indicated the intensity of color between $0.0345-0.3813$, and total phenols between 20.47 and 26.51 ppm.

\section{Key words: Cassiavera pigment, maceration, instant ginger cassiavera, functional} drink 


\section{PENDAHULUAN}

Selama ini orang menilai makanan atau minuman dari kandungan nutrisi dan kemampuannya memuaskan selera. Beberapa tahun terakhir ini, penilaian tersebut berkembang ke arah fungsi makanan atau minuman dalam mengatur metabolisme tubuh secara biologis. Pangan yang dapat memenuhi fungsi tersebut disebut sebagai makanan atau minuman fungsional. Fenomena pangan fungsional telah melahirkan paradigma baru bagi perkembangan ilmu dan teknologi pangan, yaitu dilakukannya berbagai modifikasi produk olahan pangan menuju sifat fungsional (Astawan, 2005).

Cassiavera mengandung senyawa tannin, minyak atsiri, flavonoid dan lainnya yang diduga dapat berperan sebagai antioksidan (Dalimartha, 2002). Komponen utama penyusun minyak atsiri adalah transsinamaldehid $(60.72 \%)$, eugenol (17.62\%) dan kumarin (13.39\%) (Wang, et al dalam Wijayanti, 2009). Sinamaldehid biasanya digunakan sebagai flavour dalam makanan (roti, kembang gula dan minuman ringan). Sinamaldehid berfungsi dalam pencegahan pengumpalan darah dalam tubuh sehingga dapat mengatur kadar gula dalam darah. Rasa pedas dan manis yang ditimbulkan dari produk cassiavera diakibatkan karena masih terdapatnya kandungan sinamaldehid pada produk tersebut (Yeni, 2008). Pigmen cassiavera larut dalam air memberikan warna merah sampai kecoklatan.

Kandungan tanin pada cassiavera cukup tinggi (lebih dari 10\%) (Marliyati, 1995; Hangerman. AE, 2002 ;Nacz. M, 1994) dibandingkan senyawa rempah lainnya. dan flavonoid adalah Senyawa fitokimia yang berperan sebagai antioksidan pada cassiavera (Astawan, 2010). Tanin berperan dalam mencegah atau menurunkan resiko penyakit jantung koroner.

Pengambilan pigmen pada cassiavera dilakukan melalui metoda maserasi. Maserasi merupakan proses ekstraksi atau penarikan komponen aktif dari tanaman melalui perendaman dengan pelarut selama waktu tertentu (Dinda, 2008). Ekstraksi dari suatu bahan pada prinsipnya dipengaruhi oleh suhu.
Semakin tinggi suhu yang digunakan, makin tinggi rendemen ekstrak yang diperoleh. Namun demikian bahan hasil ekstraksi dengan berbagai tingkat suhu akan memberikan pengaruh yang berbeda terhadap kualitas pigmen yang dihasilkan. Intensitas warna yang diperoleh dapat diukur menggunakan spektrofotometer pada panjang gelombang $556 \mathrm{~nm}$.

Pemanfaatan jahe dalam pembuatan minuman sering dilakukan, sebagai minuman penyegar dan penghangat tubuh. Minuman jahe sebagai minuman fungsional bermanfaat untuk sirkulasi darah dan menurunkan kadar kolesterol. Melalui ekstraksi pigmen pada cassiavera dengan metoda maserasi pada berbagai suhu dan lama waktu maserasi serta penggabungan dengan jahe pada formulasi yang sesuai, akan menghasilkan minuman instan jahe cassiavera dengan warna alami sebagai minuman fungsional yang berkhasiat bagi kesehatan tubuh.

\section{BAHAN DAN METODA}

\section{Bahan}

Bahan yang digunakan dalam penelitian ini meliputi cassiavera stik, ektrak jahe, gula, garam, air dan bahan kimia untuk pengujian.

Cassiavera (Cinnamomum burmanii) yang digunakan adalah dari pohon yang telah berumur 10 tahun yang diperoleh dari perkebunan rakyat di Kecamatan Sungai Tarab Kabupaten Batusangkar Propinsi Sumatera Barat.

Bahan kimia pengujian untuk uji total fenol seperti; etanol $95 \%$, pereaksi Folin, $\mathrm{Na}_{2} \mathrm{CO}_{3} 5 \%$, standar asam tannat.

Alat

Peralatan yang digunakan meli-puti; alat ekstraksi (skala lab), saringan, pengaduk, corong pemisah, spectrophotometer, cuvet serta alat bantu seperti penggiling, timbangan, pisau, panci pemasak stainless, serta alat-alat gelas dan peralatan pengujian. 


\section{Metoda Penelitian}

Penelitian dilakukan beberapa tahap yaitu:

Tahap 1. Penyiapan cassiavera.

Cassiavera dihaluskan sampai menjadi bentuk stik pecahan dengan ukuran 1-2 mm. Semakin halus tekstur cassiavera akan susah dipisahkan dalam penyaringan, hal ini disebabkan filtrat yang dihasilkan agak kental.

Tahap 2. Pengambilan pigmen

Pengambilan pigmen melalui ekstraksi casssiavera dengan metoda maserasi menggunakan air (sesuai perlakuan) dengan perbandingan ekstrak cassiavera dan volume air (b/v) 1:10 selama 1-3 hari (sesuai perlakuan). Larutan cassiavera yang diperoleh kemudian disaring.

Tahap 3. Pembuatan formulasi minuman jahe instan

Formulasi pigmen cassiavera dengan jahe digunakan untuk mendapatkan komposisi yang sesuai dalam minuman fungsional. Jahe cassia instan diperoleh melalui perbandingan bubuk jahe dengan volume filtrat cassiavera (b/v) kemudian ditambahkan gula pasir dan garam, diaduk dan dipanaskan dengan api sedang (70$80^{\circ} \mathrm{C}$ ). Pemanasan dihentikan apabila telah terbentuk kristal gula, selanjutnya dihaluskan dan disaring sehingga didapatkan jahe cassiavera instan dengan tekstur dan ukuran yang homogen.

\section{Rancangan Penelitian}

\section{Penelitian awal}

Pada penelitian awal dilakukan perbedaan lama maserasi dengan menggunakan pelarut air sebagai berikut :

$A=24$ jam

$\mathrm{B}=48 \mathrm{jam}$

$\mathrm{C}=72 \mathrm{jam}$
Hasil intensitas warna terbaik dari perbedaan lama maserasi cassiavera, digunakan untuk penelitian lanjutan.

\section{Penelitian Lanjutan}

Penelitian lanjutan dilakukan dengan perlakuan sebagai berikut :

$\mathrm{T}=$ Maserasi dengan air pada suhu awal:

$\mathrm{T} 1=25-27^{\circ} \mathrm{C}$

$\mathrm{T} 2=85-100^{\circ} \mathrm{C}$

$\mathrm{P}=$ Perbandingan Bubuk Jahe dengan Ekstrak Cassiavera

$\mathrm{P} 1=10: 1$

$P 2=10: 2$

$\mathrm{P} 3=10: 3$

\section{Analisis dan Pengamatan}

Pengamatan yang dilakukan terhadap jahe cassiavera instan meliputi:

1. Analisis Total Fenol

Penyiapan Sampel

Sebanyak $1 \mathrm{ml}$ filtrat sampel ditambahkan $2 \mathrm{ml}$ etanol 95\%, $5 \mathrm{ml}$ aquades dan $5 \mathrm{ml}$ pereaksi Folin. Campuran larutan tersebut didiamkan selama 5 menit kemudian ditambahkan $1 \mathrm{ml} \mathrm{Na} \mathrm{CO}_{3} 5 \%$. Campuran divortex hingga seluruh larutan merata. Campuran disimpan dalam ruang gelap selama 1 jam. Absorbansi masingmasing sampel dihitung menggunakan spektrofotometer pada panjang gelombang $725 \mathrm{~nm}$. Hasil absorbansi diplotkan dengan kurva standar asam tanat untuk diperoleh konsentrasinya.

\section{Kurva Standar}

Dibuat seri pengenceran asam tanat stok. Masing masing seri pengenceran ditambahkan $2 \mathrm{ml}$ etanol 95\%, $5 \mathrm{ml}$ aquades dan $5 \mathrm{ml}$ pereaksi folin lalu didiamkan 5 menit. Sebanyak $1 \mathrm{ml} \mathrm{Na}_{2} \mathrm{CO}_{3} \quad 5 \%$ ditambahkan dan divortex hingga rata. Seri pengenceran disimpan dalam ruang gelap selama 1 jam. Absorbansi masing-masing sampel dihitung menggunakan spektrofotometer pada panjang gelombang 556 $\mathrm{nm}$. 
2. Pengamatan Intensitas Warna.

Intensitas warna diamati dengan menggunakan Spektrofotometer dengan panjang gelombang $556 \mathrm{~nm}$

3. Uji Organoleptik terhadap minuman jahe cassiavera instan

Uji Organoleptik dilakukan pada minuman jahe cassiavera oleh panelis menurut skala hedonik terhadap warna, aroma dan rasa dengan nilai tingkat kesukaan sebagai berikut :

5 = sangat suka

4 = lebih suka

3 = suka

2 = kurang suka

1 = tidak suka

\section{HASIL DAN PEMBAHASAN}

\section{Penelitian Awal}

Pengamatan secara visual terhadap filtrat hasil maserasi berdasarkan lamanya waktu maserasi dengan menggunakan pelarut air yang dilakukan adalah seperti Tabel 1.

Tabel 1. Pengamatan visual filtrat cassiavera dari perbedaan lama maserasi

\begin{tabular}{|c|l|}
\hline $\begin{array}{c}\text { Lama } \\
\text { Maserasi }\end{array}$ & Penampakan warna \\
\hline A (24 jam) & Larutan agak merah \\
\hline B (48 jam) & Larutan merah cerah \\
\hline C (72 jam) & $\begin{array}{l}\text { Larutan merah agak } \\
\text { kecoklatan dan mulai } \\
\text { memudar }\end{array}$ \\
\hline
\end{tabular}

Pigmen cassiavera yang dihasilkan mulai dari warna agak merah sampai merah kecoklatan, dimana perbedaan lamanya waktu maserasi memberikan warna yang berbeda. Perlakuan terbaik diperoleh pada lama maserasi 48 jam (B) yang memberikan warna merah cerah, sedangkan lama maserasi 72 jam (C), warna filtrat yang dihasilkan mulai memudar karena filtrat sudah mulai ditumbuhi jamur. Untuk itu pada penelitian lanjutan digunakan filtrat cassiavera dengan lama maserasi 48 jam.

\section{Penelitian Lanjutan}

\section{Intensitas Warna Jahe Cassiavera Instan}

Hasil uji intensitas warna yang dihasilkan pada minuman instan jahe cassiavera dengan menggunakan spektrofotometer pada panjang gelombang 556 nm seperti pada Gambar 1 .

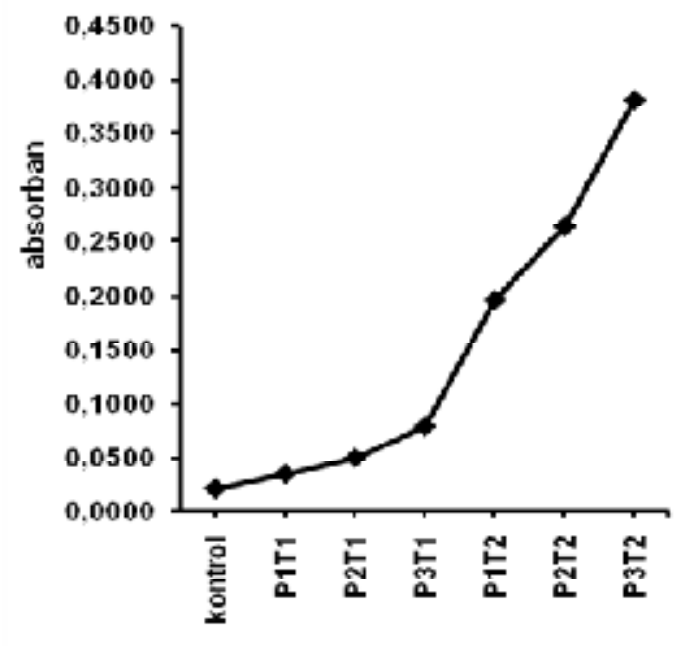

\section{Perlakuan}

Gambar 1. Intensitas warna jahe cassiavera instan

Intensitas warna meningkat dengan penambahan ekstrak cassiavera dan meningkatnya suhu maserasi dibanding kontrol. Perlakuan bubuk jahe cassiavera (10:3) dan maserasi dengan air panas (P3T2) menghasilkan intensitas warna tertinggi 0,3813 yang berbeda nyata dengan kontrol $(0,0210)$ dan perlakuan lainnya. Semakin tinggi penambahan cassiavera maka intensitas warna yang dihasilkan semakin tinggi. $\mathrm{Hal}$ ini dikarenakan cassiavera mengandung pigmen alami berupa senyawa tanin yang dapat memberikan warna pada minuman instan. Menurut Marliyati (1995), cassiavera mengandung tanin lebih $10 \%$.

Suhu juga berpengaruh terhadap intensitas warna cassiavera yang dihasilkan. Cassiavera dengan maserasi pada suhu $85-100^{\circ} \mathrm{C}$ menghasilkan intensitas warna yang lebih tinggi dibandingkan dengan suhu $25-27^{\circ} \mathrm{C}$. 
Semakin tinggi suhu yang digunakan untuk mengekstraksi zat warna tanaman maka akan dihasilkan intensitas warna yang semakin tinggi (Samsudin. AM, 2009). Disamping itu Maserasi dengan air panas menghasilkan larutan yang agak kental.

\section{Total Fenol}

Hasil analisis total fenol pada jahe cassiavera instan berkisar antara 20,4726,51 ppm seperti pada Gambar 2.

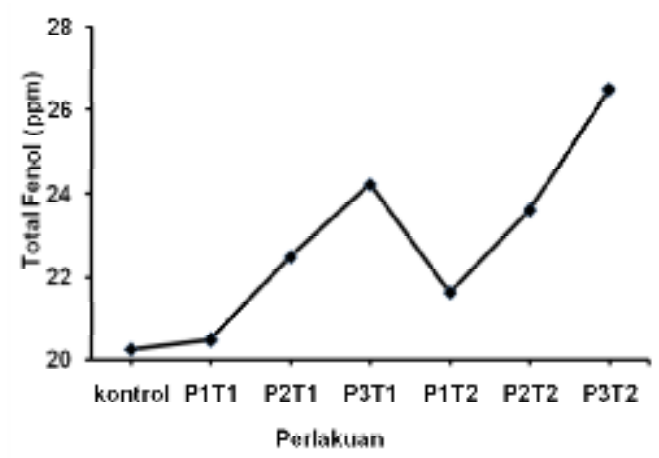

Gambar 2. Total fenol jahe cassiavera instan

Pengaruh suhu ekstraksi dan besarnya penambahan ekstrak cassiavera memberikan hasil total fenol yang berbeda. Semakin tinggi suhu dan semakin banyak ekstrak cassiavera yang digunakan memberikan total fenol yang semakin tinggi. Total fenol tertinggi dihasilkan pada perlakuan perbandingan ekstrak jahe cassiavera 10:3 dan maserasi dengan air pada suhu $85-100^{\circ} \mathrm{C}$. Menurut Azima (2004), total fenol cassiavera dapat mencapai $62,25 \%$ bila diekstrak dengan etanol.

Menurut Susanti (2008) dan Iwansyah (2009), kadar total fenol meningkat seiring dengan meningkatnya suhu ekstraksi, kemudian stabil lalu dapat menurun kembali. Tingginya suhu menyebabkan degradasi dinding sel tanaman oleh panas sehingga memudahkan keluarnya fenol dari sel tanaman.

Senyawa fenol merupakan salah satu jenis antioksidan dalam bahan pangan. Senyawa ini merupakan senyawa kimia yang mempunyai satu buah cincin aromatik yang mengandung satu atau lebih gugus hidroksi. Aktifitas antioksidan senyawa fenolik berhubungan dengan senyawa fenol (Meskin et al, 2002). Aktifitas antioksidan senyawa fenol dipengaruhi oleh beberapa faktor yaitu $\mathrm{pH}$ lingkungan, kelarutan, ketersediaan senyawa fenol dalam satu bahan dan stabilitas senyawa fenol. Menurut Azima (2004), potensi antioksidan cassiavera jauh lebih tinggi bila dibandingkan dengan BHT dan $\boldsymbol{\alpha}$-tokoferol pada konsentrasi yang sama.

\section{Uji Organoleptik Aroma, Warna, dan Rasa}

Hasil uji organoleptik terhadap aroma, warna dan rasa didapatkan seperti Gambar 3.

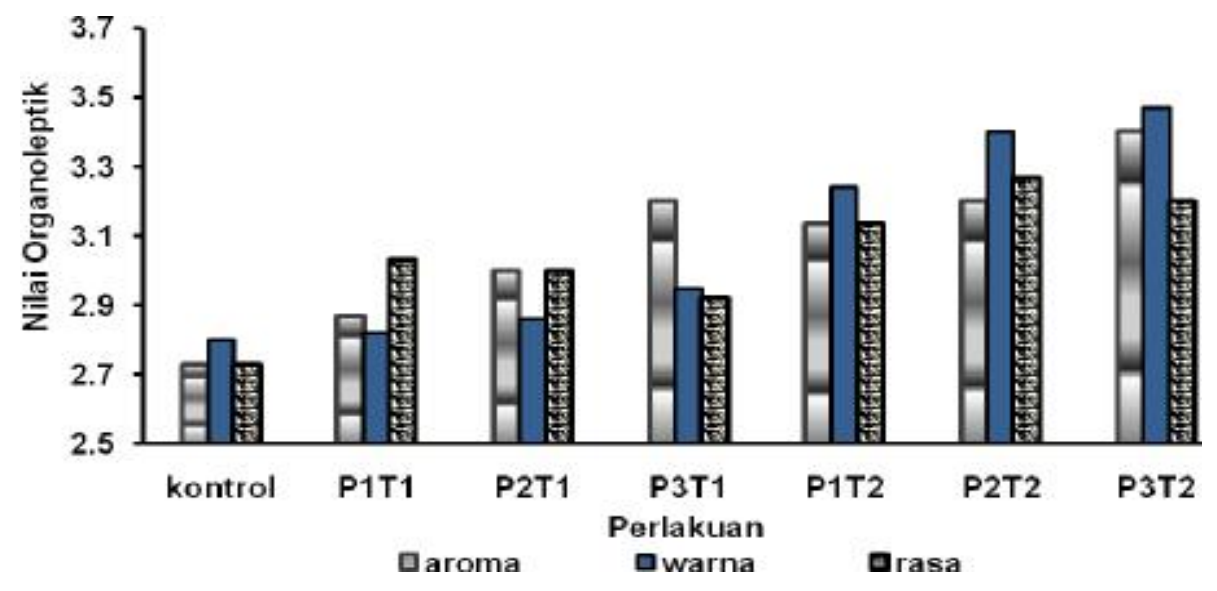

Gambar 3. Hasil uji organoleptik aroma, warna, dan rasa minuman jahe cassiavera instan. 
Dari Gambar 3 terlihat bahwa hasil uji organoletik aroma berbanding lurus dengan warna. Semakin banyak ekstrak cassiavera dan semakin tinggi suhu maserasi yang digunakan menghasilkan nilai aroma dan warna yang semakin tinggi juga. Perbandingan bubuk jahe cassiavera 10:3 dan maserasi dengan air pada suhu 85-100ㄷ (P3T2) memberikan nilai tertinggi terhadap aroma $(3,40)$ dan warna $(3,47)$. Cassiavera mengandung sejumlah besar komponen volatil yang memberikan sifat aroma dan flavor, komponen penting itu adalah sinnamaldehida dan eugenol (Rismunandar, 2001).

Untuk organoletik rasa nilai tertinggi diperoleh pada perbandingan bubuk jahe cassiavera 10:2 dan maserasi dengan air pada suhu $85-100^{\circ} \mathrm{C}$ (P2T2). Rasa pedas dan manis yang ditimbulkan dari produk cassiavera diakibatkan karena masih terdapatnya kandungan sinamaldehid pada produk tersebut (Yeni, 2008).

\section{KESIMPULAN DAN SARAN}

1. Cassiavera menghasilkan pigmen alami yang dapat dikombinasikan pada minuman jahe instan sebagai penambah pigmen alami.

2. Perlakuan perbedaan suhu dan lama maserasi memberikan nilai yang berbeda pada intensitas warna.

3. Cassiavera berpotensi digunakan untuk minuman sebagai minuman fungsional dengan total fenol 20,47$26,51 \mathrm{ppm}$ yang berfungsi sebagai antioksidan alami.

4. Perlakuan optimal pada jahe cassiavera instan adalah maserasi dengan air pada suhu $85-100^{\circ} \mathrm{C}$ selama 48 jam dan perbandingan antara bubuk jahe dengan ekstrak cassiavera (b/v) 10:3, dengan intensitas warna 0,3813 dan total fenol 26,51 ppm dan disukai panelis dengan nilai rata rata terhadap aroma 3,40 , warna 3,47 , dan rasa 3,27 .

\section{DAFTAR PUSTAKA}

Asparudin \& Tranggano, 1988. Kehilangan Minyak selama Penyimpanan Hasil Olahan Cassiavera, Skripsi Pasca Sarjana, UGM, Jogyakarta.
Astawan, M., 2005. Pangan Fungsional untuk Kesehatan yang optimal. Info Teknologi Pangan.

Astawan, M., 2010. Manfaat Kayu Manis untuk Kesehatan. http://mrwinduback2natureblogspot.com.Dikunjungi pada 15 September 2011.

Azima, F., 2004. Aktifitas Antioksidan dan Anti-agregasi Platelet Ekstrak Cassiavera (Cinnamomum burmannii Nees ex Blume) serta potensinya dalam Pencegahan Aterosklerosis pada Kelinci. Disertasi S3 IPB Bogor.

Badan Standardisasi Nasional, 1994. Standar Nasional Indonesia, SNI No. 01-3395 - 1994 tentang Casiavera Indonesia, Badan Standardisasi Nasional, Jakarta.

Dalimartha, S., 2002. Ramuan Tradisional untuk Pengobatan Kanker. Jakarta, Penebar Swadaya.

Dinas Perkebunan, 2003. Peranan Dinas Perkebunan dalam Peningkatan Mutu Cassiavera Indonesia, pada Pertemuan Teknis komoditi, Padang.

Dinda, 2008. Ektraksi. http://medicafarma .blogspot.com. Dikunjungi pada 7 September 2011.

Gomez, K.A., \& Gomez, A.A., 1983. Statistical Procedure for Agriculture Research, Second Edition, New York, John Willey and Sons.

Hangerman, A.E., 2002. Condensed tannin Struktural Chemistry Department of Chemistry. Miami, Oxford University.

Harbone, I.B., 1996. Metode Fitokimia Penuntun Cara Modern Menganalisis. Bandung.

Chandra, I.A., Setyoningrum, F., \& Herminiati, A., 2009. Pengaruh Suhu dan Waktu Penyeduhan Terhadap Sifat Fisiko-Kimia Teh Hitam Kayu 
Manis Kemasan Celup. Balai Besar Pengembangan Teknologi Tepat Guna LIPI, Subang, Jawa Barat.

Meskin, M., 2002. Phytochemical in Nutrition and Healt. London. CRC.Press

Nacz, M.T., 1994. Condensed tannins in canolahullc. Journal Agriculture Food Chemistry.

Pristiyanto, D., 2002. Pewarna Kue Yang Alami,Http://www.Suara Merdeka. com, Dikunjungi pada 2 Agustus 2011.

Rajalakshmi, D., \& Narashiman, S., 1996. Food Antioxidants Sources Health Perspective. New Yor, Inc.

Rismunandar \& Paimin, F.B., 2001. Kayu manis Budidaya dan Pengolahan, Jakarta, Penebar Swadaya.
Samsudin, A.M., \& Khoiruddin, 2009. Ekstraksi, Filtrasi Membran dan Uji Stabilitas Zat Warna dari Kulit Manggis. Skripsi pada Jurusan Teknik Kimia Universitas Diponegoro, Semarang.

Susanti, D.Y., 2008. Efek Suhu Pengeringan Terhadap Kandungan Fenolik dan Kandungan Katekin Ekstrak Daun Kering Gambir. Prosiding Seminar Nasional Teknik Pertanian, 18-19 Nofember 2008 di Jogyakarta.

Wijayanti, W.A., Zetra, Y., \& Burhan, P., 2009. Minyak Atsiri dari Kulit Batang Cinnamomum burmannii (Kayu manis) dari Famili Lauraceae Sebagai Insektisida Alami, Antibakteri dan Antioksidan. Skripsi pada Jurusan Kimia FMIPA-ITSN Surabaya.

Yeni, G., Zarlis, Firdausni, \& Anova, I.T., 2008. Stabilisasi Ekstrak Pewarna Alam sebagai Bahan Tambahan Makanan. Laporan Hasil Penelitian, Komunikasi 238 Baristand Industri Padang. 